\author{
Michał Kukliński, Matgorzata Śniegocka-Łusiewicz
}

\title{
MIARY ASOCJACJI W ANALIZIE KOSZYKOWEJ - PRZYKŁAD EMPIRYCZNY
}

\begin{abstract}
$\mathrm{Z}$ a r y s t r e ś c i. Poniższy artykuł jest próbą przedstawienia możliwości wykorzystania analizy koszykowej w badaniu zjawiska asocjacji na przykładzie danych transakcyjnych pochodzących $\mathrm{z}$ hurtowni spożywczej. Zaprezentowane zostały trzy metody analizy: uogólniona metoda indukcji reguł, a priori oraz CARMA. Zastosowanie wspomnianych reguł i analiza wyników pozwoli na uzyskanie niezbędnych informacji dla analiz marketingowych oraz daje podstawy do zastosowania w skutecznych strategiach marketingowych.
\end{abstract}

$\mathrm{S} \nmid$ o w a k 1 u c z o w e: analiza koszykowa, reguły asocjacji, GRI, a priori, CARMA.

\section{WSTĘP}

Uporządkowany zbiór danych pozwala na poznanie praw i reguł nim rządzących. Zasady te nazywamy regułami asocjacji. Odpowiednio wykonane badanie pod kątem wyszukiwania tychże reguł pozwala wyciagnąć wnioski przydatne dla badacza. Celem artykułu jest przedstawienie podstawowych wskaźników zjawiska asocjacji w analizie koszykowej na podstawie przykładu empirycznego.

Analizą koszykową, w sposób uproszczony, możemy nazwać analizę zawartości koszyka klienta. Przychodząc do sklepu (np. supermarketu, sklepu internetowego, punktu usługowego) klient ma do wyboru wiele różnego typu produktów. Do swojego „koszyka” może włożyć to, co chce, w jakiej kolejności chce i ile chce. Analiza koszykowa polega na rozpoznaniu reguł, którymi kierują się klienci przy zapełnianiu „koszyka”, zwyczajów danego klienta, prawidłowości w korzystaniu z usług danego typu, badaniu, jakie produkty kupowane są razem lub w określonej sekwencji.

Obliczenia reguł asocjacyjnych zostały przeprowadzone na danych empirycznych pochodzących $\mathrm{z}$ hurtowni spożywczej obejmujące dwa pełne lata 
sprzedaży. Hurtownia danych zawiera 238796 dokumentów sprzedaży, a w swoim asortymencie posiada 118 grup towarowych.

Pierwotna hurtownia danych zawierała 6.087 .393 rekordów, w których zostały zawarte informacje dotyczące sprzedaży, tj. numeru dokumentu sprzedaży, daty sprzedaży, kodu produktu (zawierający grupę asortymentowa), nazwę produktu, ceny, ilości, wysokości udzielonego rabatu oraz dane nabywcy.

Na potrzeby badania reguł asocjacyjnych pominięto część informacji, które opisywały sprzedaż. W celu uzyskania przejrzystego wyniku badania skupiono się na grupach towarowych produktów, a nie na poszczególnych produktach. W wyniku powyższego założenia do analizy wykorzystane zostały 2 pola hurtowni danych: numer dokumentu sprzedaży oraz numer grupy asortymentowej zawartej w każdym kodzie produktu. W związku z tym, że występowanie kilku produktów zawierających się $w$ jednej grupie asortymentowej $w$ ramach jednego dokumentu sprzedaży powodowało powtórzenia, należało dokonać grupowania. Grupowanie miało na celu doprowadzenie danych do postaci, w której dana grupa asortymentowa występowała na każdym dokumencie sprzedaży najwyżej jeden raz. W wyniku grupowania hurtownia danych zmniejszyła się do 2.373.090 rekordów.

W niniejszej publikacji przedstawione zostało każdorazowo 15 wyników poszczególnych metod analizy asocjacji: metody uogólnionej indukcji reguł (GRI), metody a priori i metody CARMA. ${ }^{1}$

\section{METODA UOGÓLNIONEJ INDUKCJI REGUŁ (GRI)}

GRI - uogólniona indukcja reguł - wskazuje występowanie asocjacji danych. Przykładowo: klienci kupujący golarki i piankę do golenia prawdopodobnie kupią również płyn po goleniu. GRI wskazuje zasady o najwyższej zawartości informacji oparte na indeksie biorącym pod uwagę zarówno uogólnienie oraz dokładność. GRI może wykorzystywać dane ilościowe oraz jakościowe, ale cel musi być jakościowy. W przypadku algorytmu a priori wszystkie dane muszą mieć charakter jakościowy, natomiast dane ilościowe można dyskretyzować, lub zastosować wspomniany algorytm GRI. GRI stosuje podejście teorii informacji, aby określić czy kandydująca reguła jest interesująca. „GRI wykorzystuje $J$-miarę.

$$
J=p(A)\left[p(A \mid B) \ln \frac{p(B \mid A)}{p(B)}+[1-p(B \mid A)] \ln \frac{1-p(B \mid A)}{1-p(B)}\right],
$$

gdzie: $p(A)$ - reprezentuje prawdopodobieństwo lub ufność obserwowanej wartości $A$. Jest to miara zakresu poprzednika; $p(B)$ - reprezentuje prawdopo-

\footnotetext{
${ }^{1}$ Opracowanie na podstawie przywołanej literatury.
} 
dobieństwo lub ufność obserwowanej wartości $B$, jest to miara zakresu następnika; $p(B \mid A)$ - reprezentuje prawdopodobieństwo warunkowe lub późniejszą ufność zmiennej $B$ dla danego $A$, które następuje.

Jest to miara prawdopodobieństwa zaobserwowania wartości $B$ pod warunkiem, że występuje $A$. Zatem, $p(B \mid A)$ reprezentuje uaktualnione prawdopodobieństwo obserwowania wartości B po zyskaniu dodatkowej wiedzy o wartości $A$. W terminologii reguł asocjacyjnych $p(B \mid A)$ jest mierzone bezpośrednio, jako ufność reguły. (...) Dla reguł z więcej niż jednym poprzednikiem, $p(A)$ jest obliczane, jako prawdopodobieństwo koniunkcji wartości zmiennych w poprzedniku" (Larose, 2006).

W przypadku tego algorytmu badacz określa maksymalną liczbę reguł, które chce osiagnąć, ponieważ znajdowanie kolejnych reguł polega na obliczaniu $J$-miary dla kolejnych przypadków i porównywaniu wartości z najniższą dostępną wartością z tabeli. Jeżeli nowa wartość jest większa, to zostaje nadpisana na poprzednią. J-miara osiaga najwyższe wartości w przypadku, gdy $p(B)$ lub $p(B \mid A)$ przyjmuje wartości skrajne, tzn. prawdopodobieństwo wynosi prawie 1 lub prawie 0 . Sytuacje, gdy poziom ufności, czyli $p(B \mid A)$, jest minimalny również są przydatne dla badacza, ponieważ umożliwiają utworzenie reguły przeciwnej (jeżeli $A$ to NIE $B$ ).

Tabela 1. Wyniki asocjacji z wykorzystaniem metody GRI

\begin{tabular}{|c|l|c|c|c|c|c|c|c|}
\hline Następnik & \multicolumn{1}{|c|}{ Poprzednik } & $\begin{array}{c}\text { Identyfi- } \\
\text { kator }\end{array}$ & Ilość & $\begin{array}{c}\text { Wspar } \\
\text { cie } \%\end{array}$ & $\begin{array}{c}\text { Poziom } \\
\text { ufności } \%\end{array}$ & $\begin{array}{c}\text { Wspar- } \\
\text { cie }\end{array}$ & $\begin{array}{c}\text { Dźwi- } \\
\text { gnia }\end{array}$ & $\begin{array}{c}\text { Wdra- } \\
\text { żalność }\end{array}$ \\
\hline sery, serki & $\begin{array}{l}\bullet \text { przetwory wa- } \\
\text { rzywne }\end{array}$ & 12 & 31411 & 13,15 & 86,82 & 11,42 & 2,341 & 1,733 \\
\hline jogurty & $\bullet \begin{array}{c}\text { sery, serki } \\
\bullet \text { desery }\end{array}$ & 3 & 31805 & 13,32 & 86,49 & 11,52 & 3,183 & 1,8 \\
\hline jogurty & $\bullet$ desery & 2 & 37228 & 15,59 & 82,98 & 12,937 & 3,054 & 2,653 \\
\hline sery, serki & $\bullet$ jogurty & 1 & 64882 & 27,17 & 81,13 & 22,044 & 2,188 & 5,127 \\
\hline $\begin{array}{c}\text { cukierki, } \\
\text { pastylki, }\end{array}$ & $\begin{array}{l}\bullet \text { czekolady } \\
\bullet \text { ciastka }\end{array}$ & 73 & 25963 & 10,87 & 74,67 & 8,119 & 2,09 & 2,753 \\
\hline $\begin{array}{c}\text { cukierki, } \\
\text { pastylki, }\end{array}$ & $\bullet$ bombonierki & 55 & 31366 & 13,14 & 74,26 & 9,754 & 2,078 & 3,382 \\
\hline jogurty & $\begin{array}{l}\bullet \text { mleka, maślanki, } \\
\text { kefiry }\end{array}$ & 4 & 43376 & 18,16 & 73,73 & 13,393 & 2,714 & 4,771 \\
\hline ciastka & $\begin{array}{l}\bullet \text { zupy w proszku } \\
\bullet \text { wafelki }\end{array}$ & 81 & 26017 & 10,9 & 73,51 & 8,009 & 2,043 & 2,887 \\
\hline ciastka & $\begin{array}{l}\bullet \text { kawy mielone } \\
\bullet \text { wafelki }\end{array}$ & 64 & 30821 & 12,91 & 73,39 & 9,472 & 2,039 & 3,435 \\
\hline
\end{tabular}


Ciąg dalszy tabeli 1

\begin{tabular}{|c|l|c|c|c|c|c|c|c|}
\hline Następnik & Poprzednik & $\begin{array}{c}\text { Identyfi- } \\
\text { kator }\end{array}$ & Ilość & $\begin{array}{c}\text { Wspar } \\
\text { cie \% }\end{array}$ & $\begin{array}{c}\text { Poziom } \\
\text { ufności \% }\end{array}$ & $\begin{array}{c}\text { Wspar- } \\
\text { cie }\end{array}$ & $\begin{array}{c}\text { Dźwi- } \\
\text { gnia }\end{array}$ & $\begin{array}{c}\text { Wdra- } \\
\text { żalność }\end{array}$ \\
\hline ciastka & $\begin{array}{l}\bullet \text { sery, serki } \\
\bullet \text { wafelki }\end{array}$ & 63 & 31648 & 13,25 & 72,96 & 9,67 & 2,027 & 3,583 \\
\hline $\begin{array}{c}\text { przetwory } \\
\text { warzywne }\end{array}$ & $\begin{array}{l}\bullet \text { dżemy, powidła, } \\
\text { konfitury }\end{array}$ & 40 & 32678 & 13,68 & 72,95 & 9,983 & 2,241 & 3,7 \\
\hline ciastka & $\begin{array}{l}\bullet \text { cukierki, pastylki, } \\
\text { draże }\end{array}$ & 31 & 46163 & 19,33 & 72,89 & 14,091 & 2,025 & 5,24 \\
\hline ciastka & $\begin{array}{l}\bullet \text { przetwory wa- } \\
\text { rzywne }\end{array}$ & 65 & 31868 & 13,35 & 72,66 & 9,697 & 2,019 & 3,65 \\
\hline ciastka & $\begin{array}{l}\bullet \text { czekolady } \\
\bullet \text { wafelki }\end{array}$ & 89 & 24891 & 10,42 & 72,56 & 7,563 & 2,016 & 2,859 \\
\hline wafelki & $\begin{array}{l}\bullet \text { batony } \\
\bullet \text { ciastka }\end{array}$ & 50 & 28274 & 11,84 & 72,44 & 8,577 & 2,308 & 3,263 \\
\hline
\end{tabular}

Objaśnienia:

Następnik - w przypadku zależności, jeżeli $A$ to $B$, jest to szukane $B$.

Poprzednik - w przypadku zależności, jeżeli $A$ to $B$, jest to szukane $A$.

Identyfikator - pozwala zidentyfikować, które reguły zostały zastosowane do danej predykcji. Numer identyfikacyjny reguły pozwala też na późniejsze dołączenie dodatkowych informacji na temat reguł takich jak wdrażalność, informacja o produkcie, poprzedniki.

Ilość - ilość przypadków; pokazuje ile jest pojedynczych przypadków o unikatowym kluczu podstawowym, dla których miała miejsce poszukiwana reguła. Oznacza to liczbę wystąpień A w całym zbiorze danych.

Wsparcie \% - Wsparciem w ujęciu procentowym (pokryciem procentowym) zbioru A nazywamy stosunek liczby transakcji wspierających A do liczby wszystkich transakcji. Innymi słowy jest to prawdopodobieństwo wystapienia zdarzenia A.

Poziom ufności \% - wskazuje on, w postaci procentowej, proporcje liczby rekordów z zarówno odpowiednim poprzednikiem oraz jego następnikiem do liczby rekordów z jedynie odpowiednim poprzednikiem. Oznacza to, iż poziom ufności jest to stosunek rekordów z A i B do wszystkich rekordów z A.

Wsparcie - pokrycie reguły w ujęciu procentowym, pokazuje udział rekordów z zarówno odpowiednim poprzednikiem jak i następnikiem w stosunku do ogólnej liczby rekordów. Jest to stosunek rekordów z A i B do wszystkich rekordów.

Dźwignia - pokazuje poziom ufności dla reguły przed prawdopodobieństwem wystapienia następnika. Oznacza to, że jeżeli mamy zasadę, jeżeli A to B to ciężarem tej zasady będzie następująca wartość: stosunek poziomu ufności dla reguły: jeżeli A to B do wsparcia reguły, jeżeli B to A.

Wdrażalność - jest procentową miarą wystapienia danych spełniających warunki poprzednika, ale niespełniających warunków następnika. W odniesieniu do zakupu produktów oznacza to, jaki odsetek klientów posiada (lub zakupiło) poprzednika, ale nie zakupiło jeszcze następnika. Statystyka wyrażalności jest określona, jako (ilość rekordów spełniająca warunek poprzednika - ilość rekordów spełniająca regułę)/ilość rekordów; gdzie spełniająca warunek poprzednika oznaczają ilość rekordów, dla których poprzednik jest prawdziwy. - ilość rekordów spełniająca regułę oznacza ilość rekordów, dla których zarówno poprzednik jak i następnik są prawdziwe. Innymi słowy wdrażalność jest to iloraz różnicy liczby A i liczba rekordów z zarówno A i B oraz sumy wszystkich rekordów.

Źródło: obliczenia własne za pomocą programu SPSS Clementine 11.1. 
Przy założonym: minimalnym pokryciu procentowym (wsparciu) na poziomie $10 \%$, najniższym poziomie ufności wynoszącym $50 \%$ oraz przy liczbie poprzedników nieprzekraczającej trzech otrzymaliśmy 100 reguł asocjacyjnych, które zostały obliczone na podstawie 238800 istotnych transakcji. Maksymalne pokrycie procentowe reguły wyniosło $37,08 \%$, najwyższy poziom ufności reguły osiagnął $86,82 \%$, dźwignia reguł zawierała się między wartościami $1,62 \%$ a $3,48 \%$.

W wyniku przeprowadzonego badania możemy zaobserwować wzajemny wpływ serów, serków i jogurtów na siebie, co obrazują wyniki z poziomem ufności przekraczającym $80 \%$, w szczególności w przypadku wyniku o identyfikatorze reguły 12 z poziomem ufności $86,82 \%$, wyniku z identyfikatorem reguły 3 oraz poziomem ufności $86,49 \%$, wynik identyfikatorze reguły $1 \mathrm{z}$ poziomem ufności $81,13 \%$, ale również wynik z niższym poziomem ufności, jednak nadal dość wysokim - 73,73\% o identyfikatorze reguły 4 . Należy zwrócić uwagę na fakt, iż reguła posiadająca najwyższy poziom ufności $(86,82 \%$, identyfikator reguły 12) dotyczy zależności serów, serków od jogurtów (przy współtowarzyszeniu przetworów warzywnych) oraz reguła posiadająca największą ilość przypadków (identyfikator reguły $1 \mathrm{z}$ poziomem ufności wynoszącym 81,13\%) również dotyczy zależności serów, serków od jogurtów, co potwierdza wcześniejszy wniosek. Pozostałe reguły dają zróżnicowane wyniki, dlatego wskazane jest badanie również innymi metodami.

\section{METODA Z WYKORZYSTANIEM ALGORYTMU A PRIORI}

Algorytm a priori wydobywa zestaw reguł $\mathrm{z}$ danych wybierając reguły $\mathrm{z}$ najwyższą zawartością informacji. Metoda a priori oferuje 5 różnych metod selekcji reguł i wykorzystuje wyrafinowany model indeksowania do wydajnego przetwarzania dużych baz danych. W przypadku dużych problemów badawczych algorytm a priori jest szybszy niż GRI, nie ma on odgórnego limitu ilości reguł, które można uzyskać i może obsługiwać reguły aż do 32 założeń. Metoda a priori wymaga, aby wszystkie dane wejściowe i wyjściowe były jakościowe, ale oferuje lepszą wydajność, ponieważ został zoptymalizowany do tego rodzaju danych. Algorytm a priori wykorzystuje właściwość a priori, która mówi o tym, że jeżeli zbiór zdarzeń $Z$ nie jest pusty, to dla dowolnego elementu $A$, gdzie $Z \cup A$ także nie będzie pusty. Oznacza to, że dodanie dowolnego artykułu do zbioru niepustego nie spowoduje, iż zbiór ten stanie się pustym. Kolejnym wnioskiem jest, iż żaden nadzbiór niepusty zbioru nie będzie pusty. Oznacza to, że poszukując zbiorów częstych algorytm najpierw przeanalizuje wszystkie jednoelementowe podzbiory i dopiero wśród tych częstych będzie szukał kandydatów na częste zbiory dwuelementowe i tak dalej. Posiadając już wszystkie zbiory częste $(k)$ algorytm wyszuka wszystkie podzbiory $(l)$ znalezionych zbiorów częstych. Następnie zbada występowanie reguły, jeżeli 1 to 
$(k-l)$. Dla podanych reguł algorytm wylicza poziom wsparcia i ufności. Od badacza zależy, jaki poziom wsparcia i ufności uzna on za minimalny dla danego badania.

Tabela 2. Wyniki analizy asocjacji z wykorzystaniem metody a priori

\begin{tabular}{|c|c|c|c|c|c|c|c|c|}
\hline Następnik & Poprzednik & $\begin{array}{l}\text { Identy- } \\
\text { fikator }\end{array}$ & Ilość & $\begin{array}{l}\text { Wspar- } \\
\text { cie } \%\end{array}$ & $\begin{array}{l}\text { Poziom } \\
\text { ufności \% }\end{array}$ & $\begin{array}{c}\text { Wspar- } \\
\text { cie }\end{array}$ & $\begin{array}{l}\text { Dźwi- } \\
\text { gnia }\end{array}$ & $\begin{array}{l}\text { Wdrażal- } \\
\text { ność }\end{array}$ \\
\hline sery, serki & $\begin{array}{l}\text { - masła } \\
\text { - jogurty }\end{array}$ & 105 & 36174 & 15,148 & 90,253 & 13,672 & 2,434 & 1,477 \\
\hline sery, serki & - desery & 6 & 37228 & 15,59 & 85,433 & 13,319 & 2,304 & 2,271 \\
\hline jogurty & - desery & 5 & 37228 & 15,59 & 82,981 & 12,937 & 3,054 & 2,653 \\
\hline sery, serki & - jogurty & 58 & 64882 & 27,17 & 81,133 & 22,044 & 2,188 & 5,126 \\
\hline sery, serki & - masła & 53 & 57812 & 24,21 & 79,143 & 19,16 & 2,134 & 5,049 \\
\hline sery, serki & - margaryny & 33 & 52184 & 21,853 & 78,25 & 17,1 & 2,11 & 4,753 \\
\hline sery, serki & $\begin{array}{l}\text { - mleka, maślanki, } \\
\text { kefiry }\end{array}$ & 41 & 55689 & 23,321 & 77,89 & 18,164 & 2,1 & 5,156 \\
\hline jogurty & $\begin{array}{l}\text { - śmietany } \\
\text { - sery, serki }\end{array}$ & 99 & 40674 & 17,033 & 74,254 & 12,648 & 2,733 & 4,385 \\
\hline jogurty & $\begin{array}{l}\text { - mleka, maślanki, } \\
\text { kefiry } \\
\text { - sery, serki }\end{array}$ & 91 & 43376 & 18,164 & 73,73 & 13,393 & 2,714 & 4,772 \\
\hline ciastka & \begin{tabular}{|l|} 
- wafelki \\
- cukierki, pastylki, \\
draże
\end{tabular} & 133 & 46163 & 19,332 & 72,89 & 14,091 & 2,025 & 5,241 \\
\hline sery, serki & - śmietany & 49 & 55929 & 23,421 & 72,724 & 17,033 & 1,961 & 6,388 \\
\hline jogurty & $\begin{array}{l}\text { - margaryny } \\
\text { - sery, serki }\end{array}$ & 81 & 40834 & 17,1 & 71,45 & 12,218 & 2,63 & 4,882 \\
\hline jogurty & $\begin{array}{l}\text { - masła } \\
\text { - sery, serki }\end{array}$ & 106 & 45754 & 19,16 & 71,356 & 13,672 & 2,626 & 5,488 \\
\hline $\begin{array}{l}\text { przetwory } \\
\text { warzywne }\end{array}$ & $\begin{array}{l}\text { - majonez, ocet, } \\
\text { musztarda }\end{array}$ & 21 & 48639 & 20,368 & 71,132 & 14,489 & 2,185 & 5,88 \\
\hline ciastka & $\begin{array}{l}\text { - chrupki, paluszki, } \\
\text { - chałwy, sękacze, } \\
\text { murzynki } \\
\text { - cukierki, pastylki, } \\
\text { draże }\end{array}$ & 115 & 38559 & 16,147 & 69,691 & 11,253 & 1,937 & 4,894 \\
\hline
\end{tabular}

Objaśnienia: patrz tabela 1.

Źródło: obliczenia własne za pomocą programu SPSS Clementine 11.1.

Przy założonym: minimalnym pokryciu procentowym na poziomie $15 \%$, najniższym poziomie ufności wynoszącym $50 \%$ oraz przy liczbie poprzedników 
nieprzekraczającej pięciu otrzymaliśmy 146 reguł asocjacyjnych, które zostały obliczone na podstawie 238796 istotnych transakcji. Maksymalne pokrycie procentowe reguły wyniosło $37,08 \%$, najwyższy poziom ufności reguły osiągnął 90,25\%, dźwignia reguł zawierała się między 1,35 a 3,46\%.

Zdecydowanie dominującym następnikiem wśród wyników z najwyższym poziomem ufności (powyżej 78\%) są sery, serki, następnie jogurty. Można zaobserwować głównie wpływ takich grup produktowych jak: masło, jogurty, desery, margaryny. Wpływ masła i jogurtu widać na wyniku o najwyższym w tej tabeli poziomie ufności 90,235\%, gdzie mamy przykład wpływu na zakup serów, serków zakupu łącznego obu produktów. Wpływ ten jest widoczny przy zakupie tychże produktów pojedynczo, jak w wynikach z poziomem ufności $81,133 \%$ oraz $79,143 \%$. Wpływ deserów, wynik z poziomem ufności $85,433 \%$ na zakup serów, serków i z poziomem ufności 82,981\% na zakup jogurtów. Wpływ margaryny - na przykładzie wyniku z poziomem ufności $78,250 \%$. Występuje charakterystyczny wzajemny wpływ serów, serków i jogurtów na siebie, co widać w regułach 105,5 i 58 , dla których każdorazowo poziom ufności przekracza $80 \%$. Metoda ta dała bardzo jednoznaczne wyniki, jednakże daje mało informacji w stosunku do potrzeb przy planowaniu kompleksowej kampanii reklamowej.

\section{METODA Z WYKORZYSTANIEM MODELU CARMA}

Model CARMA pozyskuje zestaw reguł z danych bez potrzeby specyfikacji pól wejścia (predyktor) oraz wyjścia (cel). W porównaniu do metody a priori i algorytmu GRI - CARMA dysponuje wsparciem zarówno dla poprzednika, jak i dla następnika, a nie tylko dla poprzednika. Oznacza to, że wygenerowane reguły mogą być wykorzystane do szerszego zastosowania, na przykład, aby znaleźć listę produktów lub usług (poprzednik), których następnikiem jest obiekt.

Przy założonym: minimalnym pokryciu procentowym na poziomie $10 \%$, najniższym poziomie ufności wynoszącym 50\% otrzymaliśmy 120 reguł asocjacyjnych, które zostały obliczone na podstawie 238.796 istotnych transakcji. Maksymalne pokrycie procentowe reguły wyniosło $37,08 \%$, najwyższy poziom ufności reguły osiągnął 90,66\%, dźwignia reguł zawierała się między 1,41\% a $3,35 \%$.

Bezsprzecznie widoczny jest wpływ zakupu jogurtów na zakup serów, serków, co ilustrują przykładowo wyniki z identyfikatorami reguł: 1 (poziom ufności 90,662\%), 2 (poziom ufności 90,253\%), 3 (poziom ufności 89,839\%), 5 (poziom ufności 89,049\%) oraz 7 (poziom ufności 88,722\%). Zgodnie ze specyfiką tej metody otrzymujemy również wachlarz produktów towarzyszących poprzednikom (grupa produktowa zawierająca mleka, maślanki, kefiry - wyniki o identyfikatorach reguły $1,4,6,14$; masła - wyniki o identyfikatorach reguły $2,6,8,10$; margaryny - wyniki o identyfikatorach reguły $3,4,10$; desery - wyniki o identyfikatorach reguły $5,11,13,15$; śmietany - wyniki o identyfikato- 
rach reguły $7,8,14)$. Dzięki tym wynikom oraz informacjom otrzymanym z poprzednich metod można zaplanować zintegrowane kampanie reklamowe par produktów zwiększając również sprzedaż serów, serków.

Tabela 3. Miary asocjacji z wykorzystaniem metody CARMA

\begin{tabular}{|c|c|c|c|c|c|c|c|c|}
\hline Następnik & Poprzednik & $\begin{array}{l}\text { Identy- } \\
\text { fikator }\end{array}$ & llość & $\begin{array}{l}\text { Wspar- } \\
\text { cie } \%\end{array}$ & $\begin{array}{l}\text { Poziom } \\
\text { ufności \% }\end{array}$ & $\begin{array}{l}\text { Wspar- } \\
\text { cie }\end{array}$ & $\begin{array}{l}\text { Dźwi- } \\
\text { gnia }\end{array}$ & $\begin{array}{l}\text { Wdra- } \\
\text { żalność }\end{array}$ \\
\hline sery, serki & $\begin{array}{l}\text { - Jogurty } \\
\text { - mleka, maślanki, } \\
\text { kefiry }\end{array}$ & 1 & 35275 & 14,772 & 90,662 & 13,393 & 2,445 & 1,379 \\
\hline sery, serki & $\begin{array}{l}\text { - jogurty } \\
\text { - masła } \\
\end{array}$ & 2 & 36174 & 15,148 & 90,253 & 13,672 & 2,434 & 1,477 \\
\hline sery, serki & $\begin{array}{l}\text { - jogurty } \\
\text { - margaryny }\end{array}$ & 3 & 32476 & 13,6 & 89,839 & 12,218 & 2,423 & 1,382 \\
\hline sery, serki & $\begin{array}{l}\text { - mleka, maślanki, } \\
\text { - kefiry i margaryny }\end{array}$ & 4 & 27227 & 11,402 & 89,235 & 10,174 & 2,406 & 1,227 \\
\hline sery, serki & $\begin{array}{l}\text { - jogurty } \\
\text { - desery }\end{array}$ & 5 & 30892 & 12,937 & 89,049 & 11,52 & 2,401 & 1,417 \\
\hline sery, serki & $\begin{array}{l}\text { - mleka, maślanki, } \\
\text { - kefiry i masła }\end{array}$ & 6 & 31443 & 13,167 & 88,729 & 11,683 & 2,393 & 1,484 \\
\hline sery, serki & $\begin{array}{l}\text { - jogurty } \\
\text { - śmietany }\end{array}$ & 7 & 34041 & 14,255 & 88,722 & 12,648 & 2,392 & 1,608 \\
\hline sery, serki & $\begin{array}{l}\text { - śmietany } \\
\text { - masła }\end{array}$ & 8 & 30430 & 12,743 & 87,272 & 11,121 & 2,353 & 1,622 \\
\hline sery, serki & $\begin{array}{l}\text { - przetwory } \\
\text { warzywne } \\
\text { - jogurty } \\
\end{array}$ & 9 & 31411 & 13,154 & 86,82 & 11,42 & 2,341 & 1,734 \\
\hline sery, serki & $\begin{array}{l}\text { - masła } \\
\text { - margaryny }\end{array}$ & 10 & 32394 & 13,566 & 86,791 & 11,774 & 2,34 & 1,792 \\
\hline jogurty & $\begin{array}{l}\text { - sery, serki } \\
\text { - desery }\end{array}$ & 11 & 31805 & 13,319 & 86,493 & 11,52 & 3,183 & 1,799 \\
\hline sery, serki & $\begin{array}{l}\text { - jogurty } \\
\text { - ciastka }\end{array}$ & 12 & 28616 & 11,983 & 86,455 & 10,36 & 2,331 & 1,623 \\
\hline sery, serki & - desery & 13 & 37228 & 15,59 & 85,433 & 13,319 & 2,304 & 2,271 \\
\hline sery, serki & \begin{tabular}{|l} 
- mleka, maślanki, \\
kefiry \\
- śmietany \\
\end{tabular} & 14 & 32123 & 13,452 & 84,892 & 11,42 & 2,289 & 2,032 \\
\hline jogurty & - desery & 15 & 37228 & 15,59 & 82,981 & 12,937 & 3,054 & 2,653 \\
\hline
\end{tabular}

Objaśnienia: patrz tabela 1.

Źródło: obliczenia własne za pomocą programu SPSS Clementine 11.1.

\section{PODSUMOWANIE}

Każda z prezentowanych metod badania asocjacji charakteryzuje się innymi założeniami, dlatego przedstawione wyniki analiz na tym samym zestawie da- 
nych nie są identyczne. Obliczenia w uogólnionej metodzie indukcji reguł są oparte na $J$-miarze, natomiast metoda a priori posiłkuje się różnymi metodami selekcji reguł oraz indeksowaniem danych, z kolei metoda CARMA pozwala na zdefiniowanie wskaźnika wsparcia również dla następnika. Przedstawione wyniki zostały ustawione w kolejności od najwyższego procentowego wskaźnika poziomu ufności, który właściwie odzwierciedla siłę reguły i jest najlepszym źródłem informacji o zbiorze danych. Należy zwrócić uwagę, że na pierwszym miejscu w każdej metodzie znajduje się zależność: jeżeli zakupione zostają jogurty (z towarzyszeniem drugiego składnika), to następnikiem będą sery, serki. Część wspólna wyników potwierdza tylko właściwość zastosowania kilku metod oraz daje pełniejszy obraz sytuacji. Na podstawie powyższych badań można wyciagnąc wniosek, iż kampanie reklamowe powinny skupić się na takich produktach jak: jogurty, masła, margaryny, kefiry oraz desery, ponieważ mają one najczęściej wpływ na zakup serów, serków lub jogurtów. Natomiast zakup jogurtów lub serków wpłynie na siebie nawzajem, co spowoduje, iż dzięki odpowiedniej kampanii reklamowej możemy zwiększyć sprzedaż zarówno jogurtów jak i serów, serków.

Wyniki poszczególnych metod badania asocjacji są podobne, jednak nie identyczne. Wynika to z faktu, że ilość możliwych reguł asocjacyjnych rośnie wykładniczo wraz ze wzrostem liczby atrybutów. W przedstawionym przykładzie dysponujemy 118 produktami. W obliczeniach ograniczyliśmy się wyłącznie do atrybutów binarnych (dany produkt został zakupiony lub nie), dlatego liczba spodziewanych reguł asocjacyjnych jest rzędu: $118 \times 2^{117}$. W związku z tym, że poszczególne metody nie są w stanie sprawdzić wszystkich możliwych reguł, starają się zmniejszyć przestrzeń poszukiwań. Na przykład metoda a priori wybiera spośród zbioru zdarzeń - zbiory częste, przycina je, tworząc zbiory kandydujące do poszukiwań reguł asocjacyjnych. Zupełnie odmienny sposób selekcji potencjalnych atrybutów ma metoda GRI, która opiera swój wybór kandydatów na J-miarze. Ostateczny wynik obliczeń poszczególnych metod nie będzie taki sam z uwagi na różne metody selekcji potencjalnych kandydatów branych pod uwagę przy tworzeniu reguł asocjacyjnych.

Analizy opisane w artykule mają charakter statyczny, kolejnym etapem badania będzie wprowadzenie czynnika czasu związanego z cyklicznością tygodniowă, roczną, wpływu zaistnienia świąt oraz promocji marketingowych na wyniki.

\section{LITERATURA}

Agrawal R., Imieliński T., Swami A. (1993), Mining association rules between sets of items in large databases, Proceedings of ACM SIGMOD, International Conference on Management of Data, Washington DC.

Han, Jiawei (2001), Data mining: concepts and techniques, Morgan Kaufman Publishers.

Hastie T., Tibshirani R., Friedman J. (2001), The elements of statistical learning. Data mining, inference and prediction, Springer Verlag. 
Kita R. (2002), Analiza sposobu poruszania się użytkowników po portalu internetowym, [w:] Data mining - metody i przykłady, StatSoft Polska (artykuł dostępny na stronie www.statsoft.pl/ czytelnia/dm/wstepdm.html).

Larose D. T. (2006), Odkrywanie wiedzy z danych. Wprowadzenie do eksploracji danych, Wydawnictwo Naukowe PWN, Warszawa.

Rauch J. (2005), Logic of Association Rules, [w:] Applied Intelligence 22(2005), Springer Science.

Taniar D. (2008), Data Mining and Knowledge Discovery Technologies, IGI Publishing, Hershey.

Westphal C., Blaxton T. (1998), Data mining solutions. Methods and Tools for Solving RealWorld Problems, Wiley Computer Publishing.

\section{THE ASSOCIATION MEASURES IN THE MARKET BASKET ANALYSIS - THE EMPIRICAL STUDY}

A b s tra ct. The following article is an attempt to present the use of the market basket analysis in the study of associations in the example of transaction data from the food wholesaler. Three analysis methods were presented: the GRI method, the a priori method and the CARMA method. The application of these rules and the results analysis will allow to obtain information necessary for marketing analysis and will give rise to the application of effective marketing strategies.

K e y w o r d s: market basket analysis, association rules, GRI, a priori, CARMA. 